\title{
Diferencias ambientales en el paisaje urbano de la ciudad de Querétaro, México: caso de estudio Juriquilla y Santa Rosa Jáuregui ${ }^{1}$
}

\author{
Juan Hernández-Guerrero² y Tamara Osorno-Sánchez ${ }^{3}$
}

\begin{abstract}
RESUMEN
La dinámica y evolución urbano-ambiental de la ciudad de Querétaro reconfigura paisajes y construye nuevas imágenes mentales sobre la habitabilidad urbana. El presente estudio analiza las diferencias ambientales en el paisaje urbano de Juriquilla y Santa Rosa Jáuregui, al norte de la ciudad de Querétaro, México. Se aplicó una metodología basada en un índice de calidad ambiental de paisaje urbano. El resultado fue la valoración visual de diecisiete variables urbano-ambientales agrupadas en agua, suelo y aire. Los grupos de suelo y agua dirigen el detrimento ambiental del paisaje, principalmente la basura y desperdicio de agua. Se contribuye con la identificación de zonas prioritarias para monitoreo ambiental, así también conocimiento e información para generar estrategias de planificación ambiental en espacios urbanos de rápido crecimiento.
\end{abstract}

Palabras clave: Calidad ambiental, Paisaje urbano, Valoración visual.

\begin{abstract}
The urban-environmental dynamics and evolution of the city of Queretaro reconfigures landscapes and builds new mental images on urban habitability. The present study analyzes the environmental differences in the urban landscape of Juriquilla and Santa Rosa Jauregui, north of the city of Queretaro, Mexico. A methodology was applied based on an urban landscape environmental quality index. The result was the visual assessment of seventeen urban-environmental variables grouped in water, soil and air. The groups of soil and water direct the environmental detriment of the landscape, mainly garbage and waste of water. It contributes with the identification of priority zones for environmental monitoring, as well as knowledge and information to generate environmental planning strategies in fast-growing urban spaces.
\end{abstract}

Keywords: Environmental quality, urban landscape, visual assessment.

El presente estudio forma parte del proyecto de investigación titulado "Diferenciación socio-ambiental en paisajes periurbanos de las ciudades de Querétaro y Morelia", mismo que contó con financiamiento FOFI-UAQ (Registro: 201609466). Asimismo, se otorgan especiales agradecimientos a Alma Angélica Navarrete Carrillo, Ana Karen Plaza García, María Fernanda Rodríguez Jiménez y Diana Angélica Benítez Pulido por la coordinación de equipos de trabajo, manejo de SIG y elaboración de bases de datos. Artículo recibido el 20 de enero de 2017, aceptado el 20 de octubre de 2017 y corregido el 20 de diciembre de 2017.

Universidad Autónoma de Querétaro (México).E-mail: juan.hernandez@uaq.mx

Universidad Autónoma de Querétaro (México).E-mail: tamaraoss@yahoo.com.mx 
La ciudad es la forma más excelsa del paisaje cultural al tener implícitas relaciones socio-ambientales entrelazadas en un entorno artificialmente construido (Sánchez, 2004: 120). Ese entorno recrea fondos escénicos disímiles y dinámicos traducidos en paisajes urbanos (plural) diferenciados por su uso, estructura, extensión, función y condiciones socioeconómicas (Hernández, 2015; Álvarez, 2011).

Los paisajes urbanos permiten ver la intensidad y evolución con que las ciudades modifican y reconfiguran sus entornos inmediatos (Briceño y Gil, 2003). Suelen ser tan heterogéneos según el nivel de polarización y fragmentación urbana, lo que lleva a conformar mosaicos de paisajes disgregados por estilos y formas de vida (Lalana, 2011; Gomes, 2010; Pacione, 2003; Hernández, 2015). Además, esos mosaicos permiten distinguir la especificidad de los problemas socio-ambientales al estar separados en escenarios proporcionales a los procesos de comodificación de la naturaleza (Harvey, 1997 y 2013; Prudham, 2009; Pellow, 2007).

En este sentido, los paisajes urbanos están sujetos a la interpretación perceptiva del valor visual al interior de la ciudad, esto es, imágenes y juicios gráficos y simbólicos del espacio urbano (Maderuelo, 2010; Pérez, 2000). De ahí que se forman constructos mentales de múltiples interpretaciones para otorgarles un juicio de calidad que varía según el observador y los elementos observados. La calidad puede ser valorada mediante la percepción-experiencia del ser humano, ligada a las propiedades e interpretación de la observación; cualidades y cantidades de construcciones subjetivas (Hernández, 2015; Muñoz-Pedreros, 2004; Arriaza et al., 2004). Existen trabajos científicos sobre la valoración de la calidad del paisaje urbano (Briceño y Gil, 2003; Briceño et al., 2011; Guerra, 2001; Cabreiro y Rodríguez, 2010), así como valoración ambiental del paisaje (Goddard et al., 2010; Matsuoka \& Kaplan, 2008; Luck \& Wu, 2002), pero son pocos los estudios a mesoescala que valoran la calidad urbano-ambiental. No obstante, de utilizar esa escala se pueden distinguir y evaluar diferencias ambientales en paisajes urbanos con mayor detalle, más aún en ciudades de rápida reconfiguración territorial (Hernández, 2015).

En el contexto mexicano, las transformaciones ambientales en el paisaje urbano son proporcionales a la velocidad con que las ciudades y regiones evolucionan. En el año de 1995, el sistema urbano de México estaba constituido por 347 ciudades $^{4}$ con 57.930 .996 habitantes. Para el año 2010 se contabilizaron 384 ciudades compuestas por 81.231 .281 habitantes, esto es, en quince años aumentaron en 37 el número de nuevas ciudades y en 23.300.285 la cantidad de población urbana (Vega, 2004; Secretaría de Desarrollo Social -SEDESOL- y Consejo Nacional de Población -CONAPO-, 2012). Igualmente, de las ocho regiones del territorio nacional [Noroeste, Norte, Noreste, Centro-Occidente, Centro-Este, Este, Sur y Península de Yucatán (Bassols, 1992)], la región Centro-Este (Distrito Federal, México, Puebla, Tlaxcala, Hidalgo, Morelos y Querétaro) es una de las más dinámicas, donde los paisajes de sus ciudades están en constante reconfiguración debido al grado de urbanización e industrialización.

\footnotetext{
En México, una ciudad es un centro urbano que agrupa personas en un espacio físico continuo, y donde históricamente se han manifestado realidades sociales, económicas y demográficas. El Sistema Urbano Nacional es el conjunto de ciudades de 15 mil y más habitantes y se clasifica en centro urbano (igual o mayor a 15 mil habitantes que no reúnen características de conurbación), conurbación (rango mayor a 15 mil habitantes conformado por un continuum urbano entre dos o más centros urbanos pero presentan poca funcionalidad entre ellos) y zona metropolitana (comparten una ciudad central e interrelaciones funcionales y comúnmente son mayores al millón de habitantes) (SEDESOL y CONAPO, 2012).
} 
En la región Centro-Este destaca la ciudad de Querétaro que, además de coexistir como eje económico y comercial entre el Norte y Sur del país, ha experimentado en las últimas dos décadas la intensa producción de infraestructura habitacional, industrial y comercial que transformaron paisajes tradicionales y sustituyeron sitios de actividades primarias, vegetación nativa, ríos, cuerpos de agua y áreas de preservación ecológica (García-Estrada y Hernández-Guerrero, 2015; Arvizu, 2005; González, 2012).

Al interior de la ciudad de Querétaro se observan paisajes a mesoescala con evidentes perjuicios ambientales; contaminación, escasez de vegetación, desperdicio de agua, disímil infraestructura urbana y de movilidad [Programa de las Naciones Unidas para el Medio Ambiente (PNUMA), 2008; Hernández, 2015]. Todo eso se transmite de manera cognitiva y simbólica en la revaloración del paisaje y la calidad de la habitabilidad urbana (Ellard, 2015). Además, cabe decir que el centro de la ciudad de Querétaro es constantemente atendido (el municipio de Querétaro ha sido acreedor de un premio internacional por limpieza y cuidado ambiental5) a través del esfuerzo de instancias gubernamentales mediante el monitoreo y mejoramiento ambiental; mantenimiento de sitios públicos, monitoreo de calidad del aire y agua, así como preservación de la arquitectura y adecuaciones urbanísticas.

Por otro lado, la periferia urbana es todo lo contrario, el mantenimiento es temporal y la mayoría de mejoras al paisaje quedan sujetas a las condiciones, posibilidades y estilos de vida de los pobladores, a la vez que en secciones del Sur y Norte de la periferia se acentúa el mantenimiento transitorio, mientras que el monitoreo es escaso y la ocupación de suelo es intensa (tasa de crecimiento del 2,8\%) (Hernández, 2015). Asimismo, en el Sur se respetan poco los umbrales de urbanización a pesar de contar con un área natural protegida (El Cimatario), mientras que en el Norte existe un proceso desde el año 2014 para decretar como área natural protegida a la zona Peña Colorada, pero continúa postergándose en complicidad del cambio de uso de suelo para desarrollo urbano (especialmente inmobiliarios), situación que ha favorecido la intensa construcción y reconfiguración de paisajes socio-ambientalmente heterogéneos (García, 2016).

En el año 2008, el Programa de las Naciones Unidas para el Medio Ambiente (PNUMA) señalaba la periferia Norte como un sitio de atención ambiental, dadas las amenazas de la intensa urbanización. Asimismo, Hernández (2015) realizó un estudio de paisaje basado en un método cualitativo-cuantitativo y de nueva cuenta el Norte destacó con problemáticas ambientales en agua, suelo y aire. Además, en ese sector las localidades urbanas de Juriquilla y Santa Rosa Jáuregui denotan paisajes urbano-ambientalmente heterogéneos y de rápida transformación, de ahí la importancia de realizar un estudio a mesoescala en esos lugares para identificar con mayor detalle los elementos que constituyen las diferencias ambientales en el paisaje.

Con los argumentos señalados, el objetivo del trabajo fue analizar las diferencias ambientales de los paisajes urbanos de Juriquilla y Santa Rosa Jáuregui, para ello se elaboró un índice de calidad ambiental del paisaje urbano. Derivado del trabajo se identificaron sitios prioritarios

En el año 2014 el municipio de Querétaro fue acreedor del premio Escoba de Platino en la Feria Internacional del Urbanismo y Medio Ambiente. La Asociación Técnica para la Gestión de Residuos y Medio Ambiente (Asociación española) otorga los premios denominados Escobas de Oro, Plata y Platino para reconocer a municipios, comunidades, cabildos, comunidades autónomas, empresas, ingenierías y consultorías más destacados en la gestión de residuos y limpieza urbana. El evento se celebra en España dentro del marco de actividades de la Feria Internacional del Urbanismo y Medio Ambiente. 
para mantenimiento y disposición de instrumentos de monitoreo ambiental. Al mismo tiempo se contribuye en las estrategias de planeación urbano-ambiental, donde factores como la falta de información, vigilancia y mantenimiento de espacios periurbanos, facilitan los cambios de uso de suelo, la reconfiguración territorial, el deterioro ambiental y el detrimento paisajístico.

\section{Área de estudio}

Juriquilla y Santa Rosa Jáuregui se localizan al norte de la ciudad de Querétaro (Figura Nº 1). Entre los años de 1990 y 2010 presenciaron una intensa ocupación, incluso sobre zonas de preservación ecológica y de actividades primarias, acompañado de la sobreoferta de viviendas y predios, y también la llegada de asentamientos informales; todo ello atendiendo poco las restricciones del código urbano y planes urbanos (Arvizu, 2005; PNUMA, 2008; Hernández-Guerrero et al., 2016). Al año 2010, Juriquilla estaba constituida por 13.309 habitantes y 3.774 viviendas, mientras que Santa Rosa Jáuregui por 18.508 habitantes y 4.364 viviendas.

Ambas localidades cuentan todavía con antiguos poblados, mismos que han presenciado cambios graduales en su paisaje tradicional y estructura social-económica. Alrededor de ellos, la dinámica urbana es intensa, se observa la construcción de paisajes con diferente constitución económica y residencial que influyen en la vida cotidiana de los habitantes y en el desequilibrio urbano-ambiental que impide la evolución óptima de calidad ambiental de ese sector.

Figura $\mathrm{N}^{\circ} 1$

Localización de Juriquilla y Santa Rosa Jáuregui

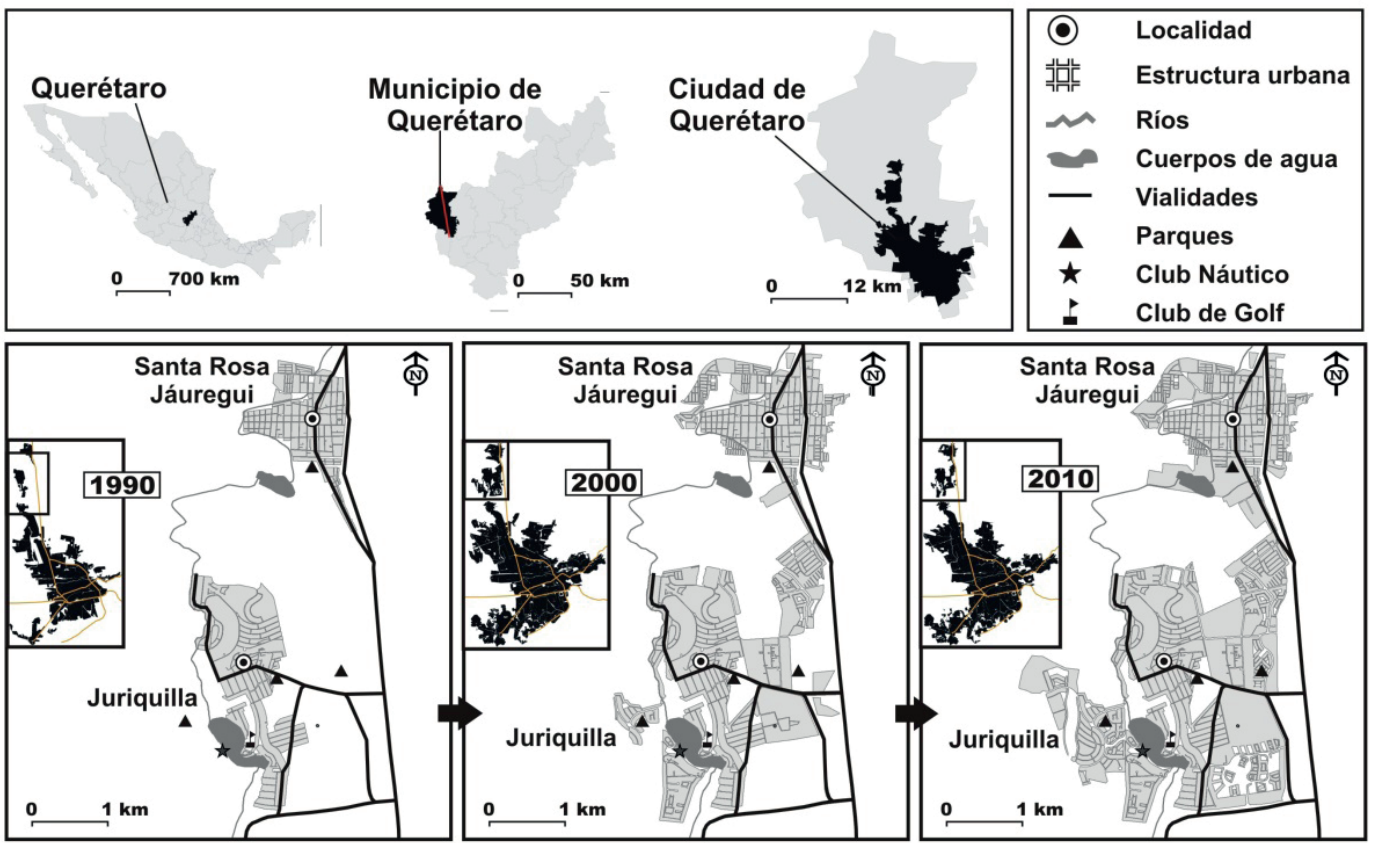

Fuente: Elaboración con base en información del INEGI (2010). 
Juriquilla se caracteriza por zonas habitacionales donde proliferan los condominios cerrados, vigilados y con diferente tipología residencial de nivel económico alto, además se cuenta con viviendas exclusivas de gran extensión (áreas residenciales de nivel económico muy alto), edificaciones en vertical y se tienen viviendas tradicionales de carácter popular, aunque estas últimas son en menor cantidad y hacinadas en el centro de la localidad, a la vez es acompañada de áreas comerciales, financieras, deportivas y de recreación (Félix, 2015). Por su parte, Santa Rosa Jáuregui presenta una mayor homogeneidad en su ocupación, ya que proliferan viviendas individuales y autoconstruidas de condiciones populares, a la vez que los elementos tradicionales juegan un papel importante; en el centro se cuenta con un kiosco (lugar de ceremonias), parroquia y centro administrativo (García-Estrada y Hernández-Guerrero, 2015). En Juriquilla, también se cuenta con comercios, pero con menor cobertura, pues se tiene mayor presencia de sitios públicos deportivos y de recreación.

Entre los rasgos biofísicos que intervienen en la calidad ambiental del paisaje, se tiene un clima semiseco (temperatura entre $7^{\circ} \mathrm{C}$ y $25^{\circ} \mathrm{C}$, y precipitación media anual de $650 \mathrm{~mm}$ ) con vegetación de matorral xerófilo y suelo de tipo vertisol pélico (arcillas expansibles de drenaje lento). El relieve es relativamente accidentado con pendientes entre el $5 \%$ y $15 \%$. Además, las localidades se encuentran cuenca abajo de la presa Santa Catarina, y cada una de ellas cuenta con un cuerpo de agua principal (el de Juriquilla forma parte de un club náutico y el de Santa Rosa Jáuregui de un parque) y un río que atraviesa de Norte a Sur.

En general, se ubican sobre sitios ambientalmente frágiles, Juriquilla colinda con áreas naturales, cuenta con un club náutico, campo de golf, jardines con vegetación exótica y largas vialidades con camellones verdes. Por otro lado, Santa Rosa Jáuregui continúa su proceso de expansión hacia áreas de cultivo y preservación ecológica de la periferia (Hernández, 2015).

\section{Materiales y métodos}

Para responder al objetivo del presente estudio se elaboró un índice de calidad ambiental del paisaje urbano (ICAPU). El índice incluye variables urbano-ambientales establecidas en el método de Hernández (2015) para la ciudad de Querétaro. Derivado de ese método se realizó una pre-selección de 27 variables (Cuadro $N^{\circ} 1$ ) las cuales fueron diseñadas con un criterio de registro establecido por la frecuencia y dominancia visual que no corresponde con la mesoescala del presente trabajo, esto implicó la selección de variables in situ (corroborar, eliminar e incluir), así como la modificación del registro. El ejercicio consistió en elaborar un cuestionario que incluía las variables (agrupadas en temas de agua, suelo y aire), descriptor de las variables (funcionalidad en el paisaje), criterios de registro (procedimiento de la valoración visual) y rango de registro (valoración visual). Después se identificaron Áreas Geoestadísticas Básicas (AGEB) (unidades censales empleadas por el Instituto Nacional de Estadística y Geografía) para delimitar el levantamiento de cuestionarios y constituir el umbral de la valoración.

Antes de iniciar fue necesario considerar que el levantamiento de información se realiza a través de recorridos (contar árboles, basura o desperdicio de agua) y puntos de observación (valoración de ríos, cuerpos de agua, flujo vehicular) sobre las vialidades para obtener la frecuencia y dominancia visual del espacio público, pues el método no está diseñado para realizar valora- 
ciones dentro de edificios, casas u otra construcción privada, ya que en ellos se suele realizar transformaciones a microescala.

Con base en el juicio descrito, el levantamiento de cuestionarios se realizó a través de recorridos aleatorios en seis AGEB definidos por las diferencias de infraestructura, equipamiento, servicios y mobiliario urbano. En cada AGEB se aplicaron dos cuestionarios en la mañana (8:0011:00h) y dos por la tarde (14:00-17:00h) durante una semana. Esos horarios corresponden con la mayor dinámica poblacional que interviene en el deterioro del paisaje y acentúa las diferencias ambientales; basura en las calles, flujo vehicular, desperdicio de agua y basura en ríos y cuerpos de agua. Los recorridos y puntos de observación fueron georreferenciados para utilizarse en un Sistema de Información Geográfica.

A partir del resultado de 28 cuestionarios se definieron 17 variables (de un total de 27) para integrar el ICAPU, en todos los casos se modificó el criterio de registro y el descriptor de la calidad ambiental (Cuadro $\mathrm{N}^{\circ} 2, \mathrm{~N}^{\circ} 3$ y $\mathrm{N}^{\circ} 4$ ). En este aspecto, cabe destacar la modificación de la variable de desperdicio de agua (ahora incluye fugas de agua, autolavados y uso irracional), así también se incluyó el flujo vehicular y funcionalidad de las calles. Por su parte, las 10 variables restantes fueron descartadas porque no permitían obtener un registro ideal a mesoescala (por ejemplo, el registro de la tonalidad del cielo para valorar contaminación atmosférica). Finalmente, se elaboraron los rangos de registro y con ello se generó la ficha de valoración ambiental del paisaje urbano para conocer las diferencias de calidad ambiental, donde 1 es la mejor calidad y 5 la peor calidad (Cuadro $N^{\circ} 5$ ).

\section{Cuadro $\mathrm{N}^{\circ} 1$}

Variables ambientales utilizadas en el cuestionario piloto

\begin{tabular}{|c|c|c|}
\hline $\begin{array}{l}\text { Variables ambientales } \\
\text { del grupo temático del } \\
\text { agua }\end{array}$ & $\begin{array}{l}\text { Variables ambientales del grupo } \\
\text { temático del suelo }\end{array}$ & $\begin{array}{l}\text { Variables ambientales del } \\
\text { grupo temático del aire }\end{array}$ \\
\hline $\begin{array}{l}\text { 1. Elementos hídricos } \\
\text { 2. Fugas de agua } \\
\text { 3. Servicios de } \\
\text { autolavado } \\
\text { 4. Alcantarillas } \\
\text { 5. Color del agua } \\
\text { 6. Olor del agua } \\
\text { 7. Basura en el agua } \\
\text { 8. Fauna feral (elementos } \\
\text { hídricos) }\end{array}$ & $\begin{array}{l}\text { 9. Pendiente del terreno } \\
\text { 10. Vegetación arbórea } \\
\text { 11. Depósito de basura en las calles (legal) } \\
\text { 12. Depósito de basura en las calles } \\
\text { (ilegal) } \\
\text { 13. Parques y jardines } \\
\text { 14. Cobertura del suelo urbano } \\
\text { 15. Vegetación arbórea dañada } \\
\text { 16. Condición de las calles } \\
\text { 17. Funcionalidad de las calles } \\
\text { 18. Cobertura de las calles } \\
\text { 19. Basura en las calles } \\
\text { 20. Tipo de basura en las calles } \\
\text { 21. Olor (depósitos ilegales de basura) } \\
\text { 22. Fauna feral (depósitos ilegales de } \\
\text { basura) }\end{array}$ & $\begin{array}{l}\text { 23. Fuentes } \\
\text { contaminantes } \\
\text { 24. Topes en las calles } \\
\text { (reductores de velocidad } \\
\text { vehicular) } \\
\text { 25. Contaminantes en el } \\
\text { aire (tonalidad del cielo) } \\
\text { 26. Temperatura } \\
\text { 27. Viento }\end{array}$ \\
\hline
\end{tabular}

Fuente: Información tomada de Hernández (2015). 
Cuadro $\mathrm{N}^{\circ} 2$

Variables ambientales utilizadas en el grupo temático del agua

\begin{tabular}{|c|c|c|}
\hline Variable & $\begin{array}{l}\text { Descriptor de la calidad } \\
\text { ambiental }\end{array}$ & Criterio del registro \\
\hline $\begin{array}{l}\text { Ríos, arroyos, } \\
\text { canales y cuerpos } \\
\text { de agua }\end{array}$ & $\begin{array}{l}\text { Presencia de agua; Indicativo de } \\
\text { vegetación; Atractivo turístico; } \\
\text { Recreación. }\end{array}$ & $\begin{array}{l}\text { Se asigna mejor calidad a la mayor } \\
\text { cantidad de elementos hídricos, inde- } \\
\text { pendiente de la dominancia y estado } \\
\text { del elemento. }\end{array}$ \\
\hline $\begin{array}{l}\text { Desperdicio de } \\
\text { agua }\end{array}$ & $\begin{array}{l}\text { Insuficiente educación y cons- } \\
\text { ciencia ambiental; Déficits en el } \\
\text { suministro de agua; Insuficiente } \\
\text { mantenimiento. }\end{array}$ & $\begin{array}{l}\text { Se valora con mayor calidad ambien- } \\
\text { tal a la menor cantidad de fugas de } \\
\text { agua en la vía pública. Se cuantifica- } \\
\text { ron aquellas fugas de agua observadas } \\
\text { fuera de las viviendas. }\end{array}$ \\
\hline $\begin{array}{l}\text { Alcantarillas y } \\
\text { bocas de tormenta }\end{array}$ & $\begin{array}{l}\text { Infraestructura hidráulica; Con- } \\
\text { trol de agua de Iluvia; Sanidad. }\end{array}$ & $\begin{array}{l}\text { Se asigna mayor calidad ambiental a la } \\
\text { mayor cantidad de alcantarillas. No se } \\
\text { incluyeron registros del drenaje. }\end{array}$ \\
\hline $\begin{array}{l}\text { Color del agua } \\
\text { de ríos, arroyos, } \\
\text { canales y cuerpos } \\
\text { de agua }\end{array}$ & $\begin{array}{l}\text { El agua en su estado puro debe } \\
\text { ser incolora. En el área urbana } \\
\text { se identificó agua transparen- } \\
\text { te, pero también se visualizaron } \\
\text { espumas, aceites, y colores obs- } \\
\text { curos indicativos de descargas } \\
\text { residuales urbanas. }\end{array}$ & $\begin{array}{l}\text { El color se eligió por la dominancia o } \\
\text { parcialidad (40\%). Se asigna mayor ca- } \\
\text { lidad al agua clara (transparente). En } \\
\text { segundo lugar, colores amarillos por la } \\
\text { presencia de tierra y residuos orgáni- } \\
\text { cos, en tercer lugar al color blanco por } \\
\text { la presencia de espumas (detergente), } \\
\text { en cuarto lugar el color café claro por } \\
\text { la presencia de aceites y en quinto lu- } \\
\text { gar el color café oscuro a negro debi- } \\
\text { do a residuos fecales y grasas. }\end{array}$ \\
\hline $\begin{array}{l}\text { Olor del agua } \\
\text { de ríos, arroyos, } \\
\text { canales y cuerpos } \\
\text { de agua }\end{array}$ & $\begin{array}{l}\text { El agua en su estado puro es ino- } \\
\text { dora. En el área urbana se puede } \\
\text { identificar olores por descargas } \\
\text { residuales, insuficiente manteni- } \\
\text { miento o mal uso de ríos y cuer- } \\
\text { pos de agua. }\end{array}$ & $\begin{array}{l}\text { Se valoró con mayor calidad a los ele- } \\
\text { mentos hídricos que no despidieron } \\
\text { olores en un rango de } 5 \text { metros de } \\
\text { distancia, mientras que la menor cali- } \\
\text { dad ambiental se presentó en los ele- } \\
\text { mentos que despidieron malos olores } \\
\text { a } 25 \text { metros de distancia del elemento } \\
\text { hídrico. }\end{array}$ \\
\hline $\begin{array}{l}\text { Presencia de basura } \\
\text { en el agua de ríos, } \\
\text { arroyos, canales y } \\
\text { cuerpos de agua }\end{array}$ & $\begin{array}{l}\text { Inadecuado mantenimiento; In- } \\
\text { salubridad. }\end{array}$ & $\begin{array}{l}\text { Se valoró con mayor calidad a los ele- } \\
\text { mentos hídricos sin presencia de basu- } \\
\text { ra, mientras la menor calidad refiere a } \\
\text { más de } 50 \text { residuos sobre la lámina de } \\
\text { agua. Este dato refiere al promedio de } \\
\text { las observaciones. Tres puntos de ob- } \\
\text { servación con duración de } 7 \text { minutos } \\
\text { en cada elemento hídrico. }\end{array}$ \\
\hline
\end{tabular}

Fuente: Información modificada de Hernández (2015). 


\section{Cuadro $\mathrm{N}^{\circ} 3$}

Variables ambientales utilizadas en el grupo temático del suelo

\begin{tabular}{|c|c|c|}
\hline Variable & Descriptor de la variable & Criterio del registro \\
\hline $\begin{array}{l}\text { Vegetación arbó- } \\
\text { rea }\end{array}$ & $\begin{array}{l}\text { Regulación térmica e hídrica; } \\
\text { reducción de contaminación } \\
\text { atmosférica; Generación de } \\
\text { biodiversidad; Calidad de } \\
\text { vida. }\end{array}$ & $\begin{array}{l}\text { Se valora con mayor calidad ambiental a las } \\
\text { unidades de análisis que contabilizaron más } \\
\text { de } 61 \text { árboles en la vía pública. Para ser con- } \\
\text { siderados en el índice debe ser }=>2 \text { metros } \\
\text { de altura }\end{array}$ \\
\hline $\begin{array}{l}\text { Vegetación arbó- } \\
\text { rea dañada }\end{array}$ & $\begin{array}{l}\text { Contaminación; insalubri- } \\
\text { dad; reducción de oxígeno; } \\
\text { Disminución de la regulación } \\
\text { hídrica y térmica. }\end{array}$ & $\begin{array}{l}\text { Se asignó mayor calidad ambiental a la au- } \\
\text { sencia de árboles dañados, mientras que la } \\
\text { menor calidad refiere a un número mayor } \\
\text { de } 61 \text { árboles con algún signo de daño. Los } \\
\text { daños refieren a árboles descortezados, pre- } \\
\text { sencia de manchas negras, quemados, con } \\
\text { plaga, por un uso inapropiado (carteles u } \\
\text { objetos insertados) o restos de hollín en sus } \\
\text { hojas. }\end{array}$ \\
\hline $\begin{array}{l}\text { Cobertura de las } \\
\text { calles }\end{array}$ & $\begin{array}{l}\text { Impactos térmicos e hídri- } \\
\text { cos; Seguridad vial; Regula- } \\
\text { ción de contaminantes. }\end{array}$ & $\begin{array}{l}\text { Se asignó mayor calidad ambiental a la co- } \\
\text { bertura de las calles con tierra debido a su } \\
\text { aporte en la regulación hídrica y térmica, } \\
\text { mientras que la menor calidad está dada por } \\
\text { calles asfaltadas debido a la ausencia de in- } \\
\text { filtración de agua, aumento de temperatura y } \\
\text { propensión a efecto invernadero. Los valores } \\
\text { dependen de la dominancia de la cobertura } \\
(60 \%) \text {. }\end{array}$ \\
\hline $\begin{array}{l}\text { Basura en las ca- } \\
\text { lles }\end{array}$ & $\begin{array}{l}\text { Insalubridad; Déficit esté- } \\
\text { tico; Inadecuado manteni- } \\
\text { miento urbano; Insuficiente } \\
\text { educación y consciencia am- } \\
\text { biental. }\end{array}$ & $\begin{array}{l}\text { La mayor calidad está dada por la ausencia } \\
\text { de algún objeto (residuo) dispuesto en la } \\
\text { calle, mientras que la menor calidad es se- } \\
\text { ñalada por un número mayor a } 91 \text { residuos. } \\
\text { Los registros contemplan por igual el tipo y } \\
\text { tamaño de los residuos. }\end{array}$ \\
\hline $\begin{array}{l}\text { Tipo de basura } \\
\text { en las calles }\end{array}$ & $\begin{array}{l}\text { Contribuye a la generación } \\
\text { de elementos tóxicos al sue- } \\
\text { lo y a la atmósfera; favorece } \\
\text { el aumento de la temperatu- } \\
\text { ra; atracción de fauna noci- } \\
\text { va. }\end{array}$ & $\begin{array}{l}\text { Se asignó mayor calidad ambiental a la au- } \\
\text { sencia de basura en las calles, mientras que } \\
\text { la menor calidad es por la presencia de re- } \\
\text { siduos plásticos que generan elementos } \\
\text { tóxicos, poca eficiencia de reciclaje y con- } \\
\text { tribución al incremento de temperatura. El } \\
\text { registro se fundamentó por la dominancia } \\
\text { del residuo (60\%). }\end{array}$ \\
\hline
\end{tabular}

Fuente: Información modificada de Hernández (2015). 
Cuadro $\mathrm{N}^{\circ} 4$

Variables ambientales utilizadas en el grupo temático del aire

\begin{tabular}{|c|c|c|}
\hline Variable & Descriptor de la variable & Criterio del registro \\
\hline $\begin{array}{l}\text { Fuentes conta- } \\
\text { minantes }\end{array}$ & $\begin{array}{l}\text { Insalubridad; ausencia o insu- } \\
\text { ficiencia de mantenimiento; } \\
\text { Amenazas ambientales. }\end{array}$ & $\begin{array}{l}\text { Se valoró con mayor calidad a las unidades } \\
\text { que no presentaron emisiones contaminan- } \\
\text { tes, mientras que la menor calidad fue por } \\
\text { la intensa dinámica vehicular por sus efectos } \\
\text { agrestes al entorno inmediato. La cobertura } \\
\text { responde a la dominancia visual del } 60 \% \text {. }\end{array}$ \\
\hline $\begin{array}{l}\text { Funcionalidad } \\
\text { de las calles }\end{array}$ & $\begin{array}{l}\text { Seguridad vial; Tránsito pea- } \\
\text { tonal y automovilístico; Fun- } \\
\text { ciones en servicios de emer- } \\
\text { gencia. }\end{array}$ & $\begin{array}{l}\text { La mayor calidad se asignó a las calles que } \\
\text { no presentaron socavones y que tuvieran } \\
\text { conexiones con otras calles. Los valores de- } \\
\text { penden de la dominancia de las calles en } \\
\text { buen estado dentro de la unidad de análisis } \\
(100 \%) \text {. }\end{array}$ \\
\hline Flujo vehicular & $\begin{array}{l}\text { Movilidad; contaminación } \\
\text { (sonora y atmosférica); acci- } \\
\text { dentes; consumo de energía } \\
\text { y espacios. }\end{array}$ & $\begin{array}{l}\text { Se valora con mayor calidad ambiental a los } \\
\text { sitios que no presenten flujo vehicular, mien- } \\
\text { tras que la menor calidad es indicada por un } \\
\text { número mayor a } 30 \text { vehículos por cada } 3 \text { mi- } \\
\text { nutos. Esto significa menor o mayor carga de } \\
\text { energía y contaminantes. }\end{array}$ \\
\hline $\begin{array}{l}\text { Topes (reducto- } \\
\text { res de velocidad } \\
\text { vehicular) }\end{array}$ & $\begin{array}{l}\text { Seguridad vial y peatonal; Re- } \\
\text { ducción de velocidad auto- } \\
\text { movilística. }\end{array}$ & $\begin{array}{l}\text { Se valora con mayor calidad ambiental a las } \\
\text { unidades sin topes, pero la menor calidad } \\
\text { es indicada por un número mayor a } 7 \text { topes, } \\
\text { esto refiere a una mayor descarga de emi- } \\
\text { siones contaminantes al cambiar a marchas } \\
\text { altas por la acción de acelerar y desacelerar. }\end{array}$ \\
\hline Temperatura & $\begin{array}{l}\text { Energía calorífica; transferen- } \\
\text { cia de energía. }\end{array}$ & $\begin{array}{l}\text { Se asigna mayor calidad ambiental a los va- } \\
\text { lores de temperatura templada, la cual bene- } \\
\text { ficia las actividades humanas y biológicas. } \\
\text { Además, presenta relación con la mitigación } \\
\text { de islas de calor. Los registros resultan del } \\
\text { promedio de tres puntos de observación y la } \\
\text { escala se realizó con ayuda de un termóme- } \\
\text { tro digital. }\end{array}$ \\
\hline Viento & $\begin{array}{l}\text { Agente de transporte; dismi- } \\
\text { nuye temperaturas altas; Disi- } \\
\text { pa emisiones contaminantes. }\end{array}$ & $\begin{array}{l}\text { Se valora con mayor calidad los registros con } \\
\text { brisa ligera, ya que las emisiones inician su } \\
\text { disipación. Los registros resultaron del pro- } \\
\text { medio de tres puntos de medición con un } \\
\text { anemómetro. Los rangos fueron adaptados } \\
\text { de la escala estándar de Beaufort. }\end{array}$ \\
\hline
\end{tabular}

Fuente: Información modificada Hernández (2015). 


\section{Cuadro $\mathrm{N}^{\circ} 5$}

Rangos de registro de la ficha de valoración ambiental del paisaje urbano

\begin{tabular}{|c|c|c|c|c|c|}
\hline \multirow{2}{*}{ Variables ambientales } & \multicolumn{5}{|c|}{ Calidad ambiental del paisaje / Rango del registro } \\
\hline & 1 & 2 & 3 & 4 & 5 \\
\hline Presencia de ríos y cuerpos de agua & $>6$ & 4 a 5 & 2 a 3 & 1 & 0 \\
\hline $\begin{array}{l}\text { Presencia de sitios con desperdicio de } \\
\text { agua }\end{array}$ & 0 & 1 a 2 & 3 a 4 & 4 a 5 & $>7$ \\
\hline Presencia de alcantarillas & $>9$ & 7 a 9 & 4 a 6 & 1 a 3 & 0 \\
\hline Color del agua (ríos y cuerpos de agua) & Claro & Amarillo & Blanco & Café & Negro \\
\hline $\begin{array}{l}\text { Olor del agua (distancia respecto al río o } \\
\text { cuerpo de agua) }\end{array}$ & $<5 \mathrm{~m}$ & $10 \mathrm{~m}$ & $15 \mathrm{~m}$ & 20 & $=>25 \mathrm{~m}$ \\
\hline Basura en ríos y cuerpos de agua & 0 & $1-20$ & $11-30$ & $21-40$ & $>50$ \\
\hline Presencia de vegetación arbórea & $>61$ & $60-41$ & $40-21$ & $20-1$ & 0 \\
\hline Presencia de vegetación arbórea dañada & 0 & $1-20$ & $21-40$ & $41-60$ & $>61$ \\
\hline Presencia de basura en las calles & 0 & $1-30$ & $31-60$ & $61-90$ & $>91$ \\
\hline Tipo de basura en las calles & $\begin{array}{l}\text { Sin ba- } \\
\text { sura }\end{array}$ & Papel & Madera & Metal & Plástico \\
\hline Tipo de cobertura de las calles & Tierra & $\begin{array}{l}\text { Empedra- } \\
\text { do }\end{array}$ & Adoquín & $\begin{array}{l}\text { Chapo- } \\
\text { pote }\end{array}$ & Asfalto \\
\hline Tipo de fuentes contaminantes & $\begin{array}{l}\text { Sin emi- } \\
\text { sión }\end{array}$ & $\begin{array}{l}\text { Habita- } \\
\text { cional }\end{array}$ & $\begin{array}{l}\text { Comer- } \\
\text { cial }\end{array}$ & Industrial & $\begin{array}{l}\text { Automó- } \\
\text { vil }\end{array}$ \\
\hline Funcionalidad de las vialidades & $\begin{array}{l}\text { Muy } \\
\text { buena }\end{array}$ & Buena & $\begin{array}{l}\text { Modera- } \\
\text { da }\end{array}$ & Mala & Muy mala \\
\hline Flujo vehicular & 0 & 1 a 10 & 11 a 20 & 21 a 30 & $>30$ \\
\hline Presencia de reductores de velocidad & 0 & $1-2$ & 3-4 & $5-6$ & $>7$ \\
\hline Temperatura & 15 a $19^{\circ} \mathrm{C}$ & 20 a $23^{\circ} \mathrm{C}$ & 24 a $27^{\circ} \mathrm{C}$ & 28 a $31^{\circ} \mathrm{C}$ & $>32^{\circ} \mathrm{C}$ \\
\hline Viento & $\begin{array}{l}\text { Brisa } \\
\text { ligera }\end{array}$ & $\begin{array}{l}\text { Brisa mo- } \\
\text { derada }\end{array}$ & $\begin{array}{c}\text { Brisa } \\
\text { fresca }\end{array}$ & $\begin{array}{l}\text { Brisa } \\
\text { fuerte }\end{array}$ & $\begin{array}{l}\text { Viento } \\
\text { fuerte }\end{array}$ \\
\hline
\end{tabular}

Fuente: Resultados del cuestionario de campo.

La ficha de valoración ambiental del paisaje urbano se aplicó en 20 AGEB (cubren la totalidad de Juriquilla y Santa Rosa Jáuregui); tres veces por la mañana y tres veces por la tarde (8:00-11:00h y 14:00-17:00h) durante tres periodos (julio-septiembre y octubre-diciembre) para el año 2015 y un periodo (enero-junio) del 2016. En total se levantaron 320 fichas por 15 personas mayores de 18 años, ajenas al AGEB y previamente capacitadas. En cada recorrido y punto de observación se requirió un mínimo de tres personas para realizar la valoración, con ello se pudo homogeneizar los registros y disminuir sesgos en la puntuación de las variables urbano-ambientales, tal como lo señala Stewart et al. (1983) para evaluaciones cualitativas-cuantitativas. 
Con los resultados de las fichas se elaboró y diseñó la base de datos en una hoja de cálculo. Después se realizaron gráficos de cajas para identificar las variables con mayor y menor calidad según grupo temático y AGEB. Posterior a ese ejercicio se realizaron bases de datos de forma individual (por variable) según grupo temático con el objeto de exportarlas al Sistema de Información Geográfica (SIG) para elaborar capas (layers) de puntos en formato vectorial y después transformarlos a formato raster. Para la transformación a raster se requirió del método de interpolación de distancia inversa (IDW), el cual generó la continuidad espacial respecto a la proximidad del valor con el punto más cercano de cada variable y grupo temático.

Con los resultados de la interpolación, se utilizó álgebra de mapas en el SIG para correlacionar las capas por grupo temático de agua, suelo y aire. Este procedimiento otorgó más clases de las ya contempladas, por esa razón se aplicó una reclasificación de intervalos iguales en cinco clases: 1=Muy alta, 2=Alta, 3=Media, 4=Baja y 5=Muy baja. En este caso, la calidad Muy alta significa una correlación de variables que denotaron la mejor calidad ambiental del paisaje urbano (poca basura, ríos o cuerpos de agua con mantenimiento, poco flujo vehicular, entre otros), mientras que la calidad Muy baja refiere a una calidad ambiental deficiente o mala (exceso de basura, ríos o cuerpos de agua con basura y malos olores, entre otros). Finalmente, se elaboró y diseñó la cartografía temática y con ello la identificación de sectores prioritarios de atención ambiental a mesoescala. Para acompañar este último paso se incluyó información en formato vectorial para el diseño cartográfico, sean curvas de nivel, límites administrativos, ríos y cuerpos de agua y sitios de interés.

A partir de este momento y con el fin de tener una lectura óptima de los resultados, se denominará "nivel de calidad ambiental en el paisaje urbano" a la valoración del conjunto de variables por grupo temático (por ejemplo, nivel de calidad ambiental del paisaje urbano para agua, suelo o aire), mientras que a la suma de los tres grupos temáticos se le denominó "calidad ambiental del paisaje urbano".

\section{Calidad ambiental del paisaje urbano en Juriquilla y Santa Rosa Jáuregui}

La valoración del grupo temático del agua demostró que Santa Rosa Jáuregui presenta un nivel de calidad bajo, mientras que Juriquilla corresponde al nivel medio (Figura $N^{\circ} 2$ ). Se observó que la problemática principal en Santa Rosa Jáuregui refiere al río y cuerpo de agua principal. El río presentó malos olores, basura y colores obscuros. En la parte alta y media del río se identificaron residuos sólidos (predominio de material plástico) de diferente tipo y tamaño, mientras que en la parte baja del río se identificaron residuos de gran tamaño, así como grasas y vísceras de animales que obstruyen de manera parcial el cauce, situación que es aludida al mal uso del río y el drenaje de la zona. Esto refuerza lo planteado por García-Estrada y Hernández-Guerrero (2015), los cuales señalan que en el temporal de lluvias (mayo-octubre) el río presenta constantes desbordamientos provocando inundaciones (detrimentos a la salud y actividades cotidianas) que, entre otras causas, se relaciona con residuos sólidos. Por otro lado, el cuerpo de agua se valoró con calidad media, pues a pesar de ser un sitio de ocio y recreación como lo es un parque, se visualizaron residuos sólidos y se detectó un sutil mal olor. 
Figura $\mathrm{N}^{\circ} 2$

Valoración del grupo temático del agua

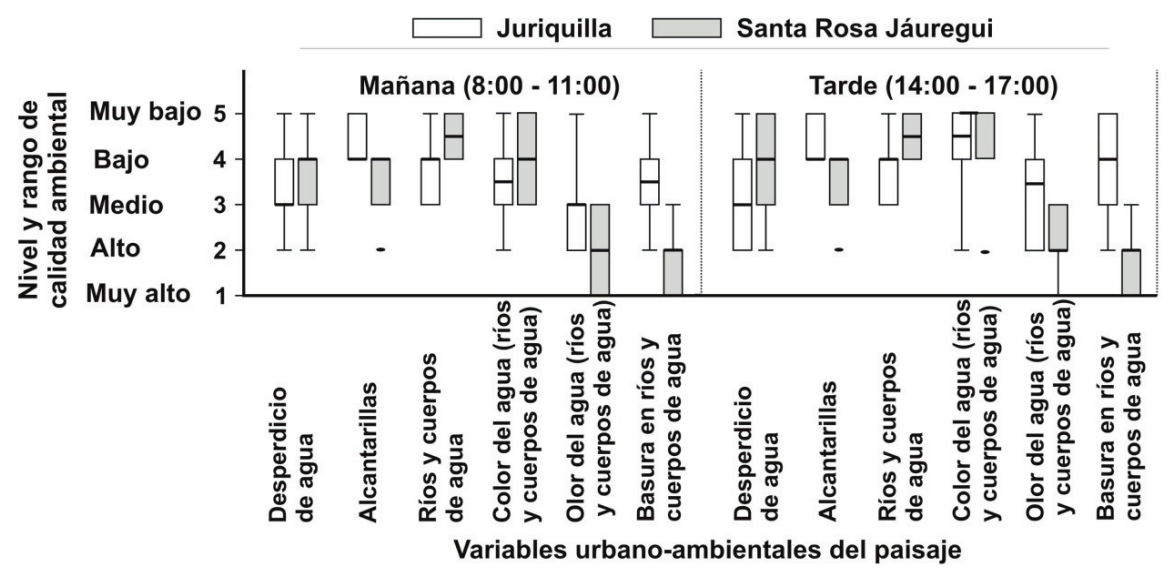

Fuente: Resultados de la ficha de valoración ambiental del paisaje urbano.

En Juriquilla, el río y cuerpo de agua fueron valorados con alta calidad ambiental del paisaje, pero la calidad del grupo temático disminuyó con la variable de desperdicio de agua. El desperdicio se observó a través de fuentes artificiales de agua en las entradas de conjuntos habitacionales. También se observó el riego o sobreriego de grandes camellones, glorietas, jardines y el campo de golf, mismos que tienen vegetación exótica y extensas áreas de césped, todo ello requiere de importantes cantidades de agua, al tiempo que el regado se realiza en horas del día con mayor temperatura y radiación solar (11:00 h y 16:00 h). Si bien, se utiliza el re-uso del agua, se aprecia derroche y gasto innecesario. Esto contrapone algunos requerimientos hídricos óptimos para áreas verdes urbanas, sea el caso del uso de especies nativas, sistemas de riego eficientes (adecuada dosis y forma de aplicación de riego con aguas residuales) y conservación de especies locales (Braatz y Kandiah, 2004; Domene y Saurí, 2003).

Por otro lado, los resultados del grupo temático del suelo señalan que Santa Rosa Jáuregui presenta una mala calidad ambiental del paisaje urbano, mientras que Juriquilla se encuentra entre media y baja (Figura $N^{\circ} 3$ ). Las variables de vegetación arbórea y basura fueron determinantes para definir la calidad. Ambas localidades al encontrarse en la periferia urbana disponen de vegetación nativa a sus alrededores, pero en el entorno inmediato la situación cambia, pues en Santa Rosa Jáuregui es notoria la ausencia de árboles en la mayoría de las AGEB, solo cuatro de esas unidades presentaron hasta 40 árboles, y los otros cuatro no superaron los 20 árboles. En Juriquilla la situación fue distinta, ya que el promedio fue mayor a 61 árboles por AGEB aunque predomina la vegetación exótica.

La Organización Mundial de la Salud señala que, para satisfacer el oxígeno diario por cada persona, son necesarios 22 árboles, situación que no se cumple en la mitad de los AGEB de Santa Rosa Jáuregui, específicamente en la zona Centro con más de 1.000 habitantes. Este resultado afirma lo señalado por Hernández (2015), el cual indicó que hacia el Norte de la ciudad existen 
Figura $\mathrm{N}^{\circ} 3$

Valoración del grupo temático del suelo

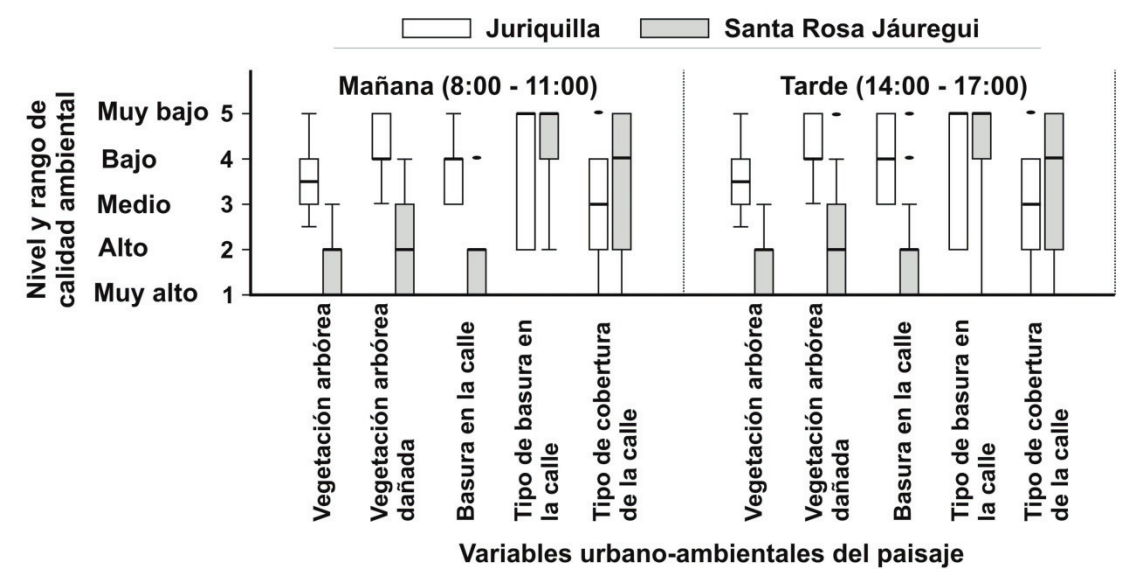

Fuente: Resultados de la ficha de valoración ambiental del paisaje urbano.

zonas con 15 y 20 árboles, así en el caso de Santa Rosa Jáuregui además los árboles presentan daños considerables; contaminados, descortezados, talados y utilizados como mobiliario urbano.

En lo que respecta a la variable de la basura, Juriquilla presentó muy alta calidad ambiental del paisaje, solo en el antiguo poblado se observó problemáticas de basura (alcanzó un máximo de 250 residuos en toda la AGEB), el resto de las AGEB presentan un patrón de limpieza, al tiempo que se observó personal del municipio aseando las calles. Por otro lado, Santa Rosa Jáuregui presentó muy mala calidad, pues los residuos identificados de la calle, ríos y cuerpos de agua promediaron 500 residuos sólidos de diferente tamaño y material por AGEB.

A fin de discutir ese resultado y tener una representatividad de residuos sólidos, se tomó el caso de una AGEB en Santa Rosa Jáuregui. En esa unidad se recolectaron y pesaron aquellos residuos plásticos (residuos predominantes) como botellas de PET, envoltorios, bolsas y diversos residuos sin forma y tamaño específico (entre $5 \mathrm{~cm}$ y $40 \mathrm{~cm}$ ). En total fueron 300 residuos los que se pesaron con un resultado de $12 \mathrm{~kg}$ aproximadamente. Si la misma cantidad se contabilizara en todas las AGEB de Santa Rosa Jáuregui, alcanzaría una cantidad de $96 \mathrm{~kg}$, equivalente al $1 \%$ del total de la basura registrada en la ciudad (900 toneladas diarias).

Finalmente, el grupo temático del aire fue el más contrastante (Figura $\mathrm{N}^{\circ} 4$ ), tanto en hora del día como en zonificaciones. Los resultados indicaron mala calidad del aire en Santa Rosa Jáuregui y nivel medio en Juriquilla. En las dos localidades la variable vehicular fue el principal factor de detrimento ambiental, asociado a que cada una de ellas cuenta con una vialidad principal transversal de Sur a Norte. Los registros de flujo vehicular en esas vialidades principales fueron de 40.8 vehículos en promedio por cada tres minutos para Juriquilla, mientras que en Santa Rosa Jáuregui fue de 33,6 vehículos. Cabe resaltar que en los horarios de mayor dinámica (8:00-11:00h y 14:00-17:00h) se contabilizaron, en los mismos tres minutos, hasta 97 vehículos en Juriquilla y 55 en Santa Rosa Jáuregui. Adicional a esto, se identificó que 5 de cada 10 vehículos son de gran 
capacidad (Minivan, Sport Utility Vehicle (SUV) y pick up), y de esos 5 vehículos, 3 transportaban una sola persona.

Figura $\mathrm{N}^{\circ} 4$

Valoración del grupo temático del aire

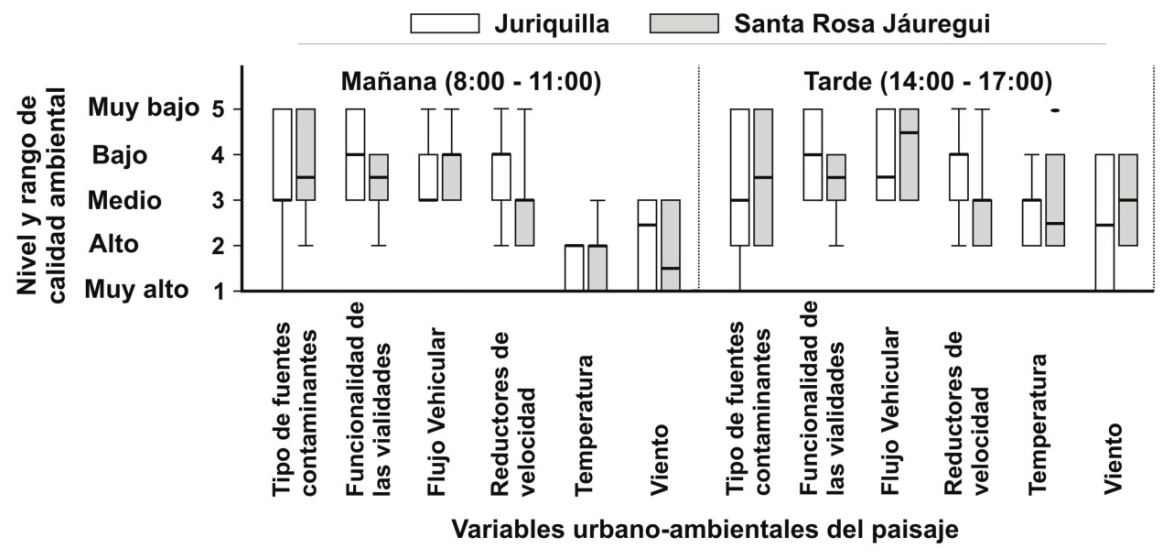

Fuente: Resultados de la ficha de valoración ambiental del paisaje urbano.

Otra vialidad cercana y que recorre el costado Este de los dos lugares, es la carretera Querétaro-San Luis Potosí. En esa vialidad de ocho y diez carriles, se registró un promedio de 5.100 vehículos en una hora, esto es, un promedio de 103,4 vehículos por minuto. Los datos de flujo vehicular marcan un parteaguas importante en la calidad ambiental del paisaje, pues en un estudio realizado a cinco ciudades mexicanas (Chihuahua, Tepic, San Luis Potosí, Villahermosa, Chilpancingo y Veracruz), la ciudad de San Luís Potosí (ciudad vecina de Querétaro) resultó ser la más alta con un promedio de 4.000 vehículos por hora y 37,5 vehículos por cada tres minutos (Tejeda Le Blanc \& Cía, S.C., 2009). Así, los resultados del presente trabajo rebasaron la cantidad de flujo vehicular de ese estudio en 1.100 vehículos por hora y en 3,3 cada tres minutos.

También se identificaron congestionamientos viales (tránsito lento) entre las 14:00 horas y 16:00 horas. Si bien el congestionamiento vial se vincula con la cantidad de vehículos y la hora del día, también se relaciona con las variables de funcionalidad, cobertura y reductores de velocidad en la calle, estas variables en su conjunto, determinaron el nivel bajo de calidad para Santa Rosa Jáuregui y nivel medio en Juriquilla. Otras variables que se ligaron con el tráfico vehicular, y donde los registros se presentaron homogéneos, fue en la oscilación térmica (entre $20^{\circ} \mathrm{C}$ y $31^{\circ} \mathrm{C}$ ) y velocidad del viento (fluctuó entre calmo y brisa moderada), pues colaboran en la formación de puntos críticos de calor y concentración de contaminantes, especialmente en Juriquilla entre las 8:00-9:00 horas y las 14:00-16:00 horas.

\section{Diferencias ambientales en el paisaje urbano de Juriquilla y Santa Rosa Jáuregui}

La diferencia de la calidad ambiental del paisaje urbano es el resultado de la relación de las variables de los tres grupos, así como su valoración en la mañana y en la tarde. Por lo tanto, de ma- 
nera general, la calidad ambiental del paisaje urbano en Juriquilla fue definida con un nivel medio, mientras que Santa Rosa Jáuregui presenta un nivel bajo (Figura $N^{\circ} 5$ ). En lo particular se encontraron algunas zonas con niveles bajos, Juriquilla registró 2 AGEB con nivel bajo (Centro y Sur) constituidos por 8.108 habitantes y 2.462 viviendas, equivalente a $61 \%$ y $65 \%$ del total respectivamente. En Santa Rosa Jáuregui el nivel bajo está representado a través de 8 AGEB (Centro, Sur y Norte) formados por 8.041 habitantes y 1.940 viviendas, equivalente al $43 \%$ y $44 \%$ del total respectivamente.

Lo anterior se resume que en Juriquilla a pesar de percibir alto nivel económico de la mayoría de sus habitantes, la calidad ambiental no es la ideal. Si bien el paisaje es acompañado de conjuntos habitacionales (mayoritariamente cerrados y vigilados) que gozan de servicios y amenidades ambientales al interior del clúster (acompañados de un discurso sobre el cuidado ambiental y estética urbana individual), al exterior que, es el objetivo de este trabajo, las vialidades son escasas y poco funcionales, al tiempo que fomentan el uso de automóviles y presentan extensos camellones con áreas verdes (con vegetación exótica) que consumen importantes cantidades de agua (Figura $\mathrm{N}^{\circ} 5$ ). Además, la apropiación de ríos y cuerpos de agua para recreación (Club náutico) ha promovido paisajes polarizados. Por otro lado, en Santa Rosa Jáuregui el paisaje está descuidado y se han conformado sitios inseguros y de difícil acceso. Las vialidades son poco funcionales, pero excluyendo la avenida principal, el resto de ellas no presenta tráfico vehicular pesado. Además, todas las calles, ríos y cuerpos de agua exhiben residuos sólidos, mientras que la vegetación es escasa y la existente se encuentra dañada. Con lo anterior, se pone de manifiesto que las diferencias ambientales deben verse como la interconexión de variables, y no solo como la estética urbana donde existe una carga específica a cierta variable y se descuida el resto de ellas.

Figura $\mathrm{N}^{\circ} 5$

Calidad ambiental del paisaje urbano
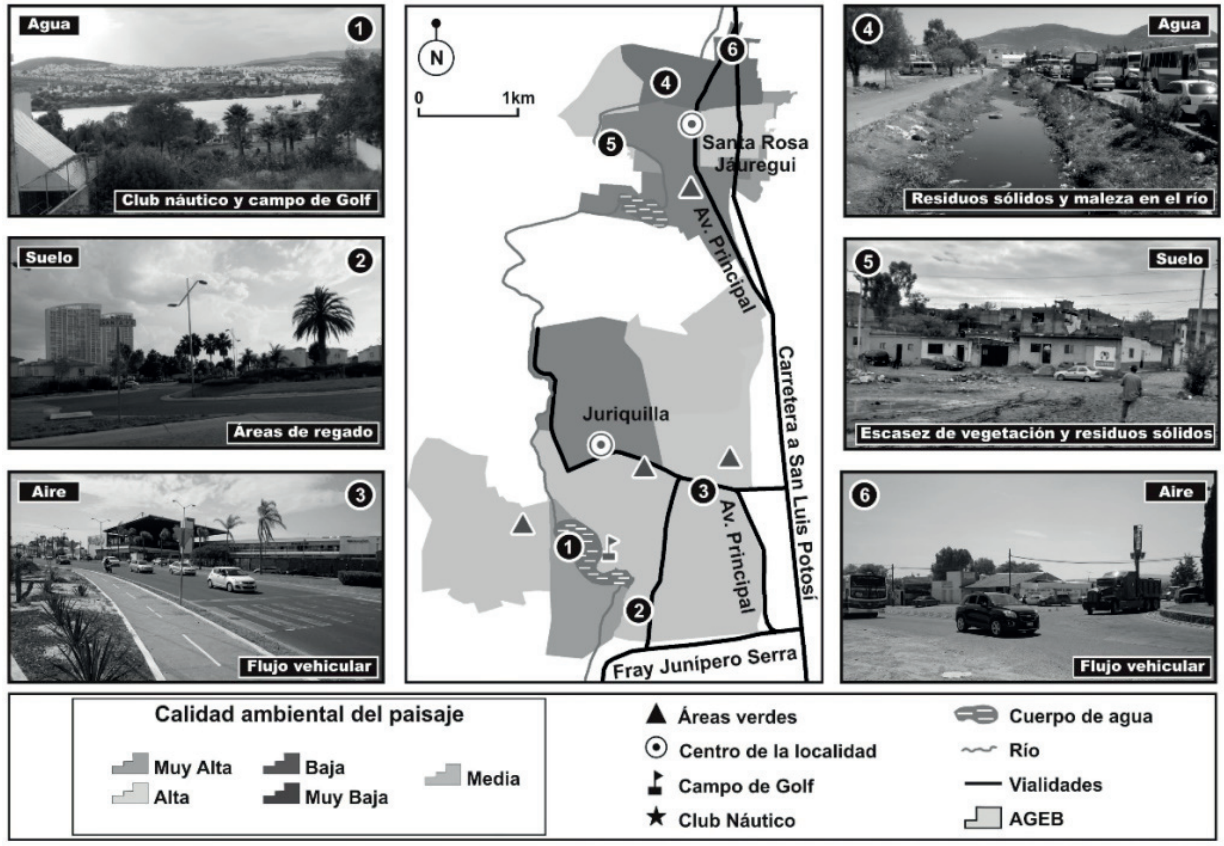

Fuente: Elaboración propia y fotografías del autor, noviembre 2016. 
Es importante decir que el municipio de Querétaro realiza constantemente mantenimiento urbano, pero en estas zonas se prioriza el centro urbano por lo que se descuidan el resto de la localidad, además la Secretaría de Desarrollo Sustentable de Querétaro realiza periódicamente monitoreo atmosférico en la ciudad, pero no para estas zonas de la periferia urbana. Es en este sentido que los aportes del presente trabajo cobran importancia, pues con esta técnica se apoya la identificación y monitoreo de sitios que apoyen la vigilancia ambiental, se establezcan redes ciudadanas y permita la instalación de instrumentos de monitoreo ambiental.

La Figura $N^{\circ} 6$ muestra la identificación y distribución de 42 sitios prioritarios para la atención ambiental. Las tres variables con mayor distribución y repercusiones ambientales son el desperdicio de agua, la basura en las calles y la emisión de contaminantes por vehículos. Los sitios además de identificar el problema, tratan de apoyar la concientización ambiental, las estrategias para la instalación de equipo de monitoreo y las actividades de mantenimiento; pues son algunos de los muchos factores que se observaron a lo largo del trabajo. Por otro lado, también pueden ser considerados un aporte estratégico en el ordenamiento territorial y en la planeación urbana, pues señalan un eslabón en la cadena de problemáticas ambientales que disminuiría las diferencias ambientales y mejoraría la calidad de vida y habitabilidad urbana.

Figura $N^{\circ} 6$

Sitios prioritarios para la atención ambiental del paisaje urbano

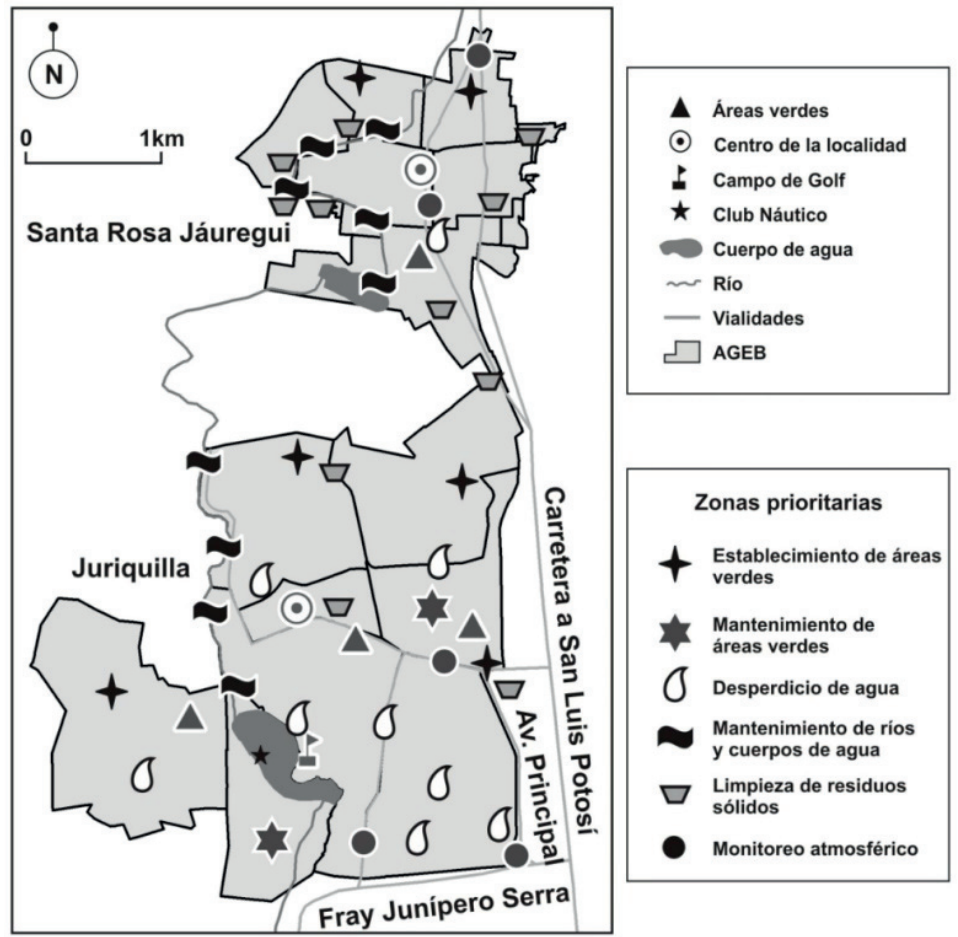

Fuente: Resultados de la ficha de valoración ambiental del paisaje urbano. 


\section{Conclusiones}

Los resultados permitieron identificar que las diferencias ambientales del paisaje urbano están representadas por la interrelación de los tres grupos temáticos, pero el grupo de suelo y agua son los que acentúan los problemas ambientales. Al mismo tiempo, el enfoque sistémico del análisis permitió identificar asociaciones de variables que sobresalen del resto, sea el caso de la basura y contaminación en calles, ríos y cuerpos de agua, desperdicio de agua, vegetación arbórea escasa y dañada, así como deficiente funcionalidad de calles. Además, se pudo observar que las desigualdades como la estética urbana, infraestructura y servicios, son aristas del paisaje urbano que intervienen en la polarización y acentúan las diferencias ambientales.

Al respecto, Juriquilla presenta problemas ambientales que se ocultan entre la estética urbana y se transforman en externalidades, aun así el método consiguió identificarlos y reconocer que la calidad ambiental no es la ideal a pesar de tener mejor infraestructura, atención oficial y mantenimiento, así como alto nivel económico de la mayoría de sus habitantes; en este caso se otorga mayor atención a la imagen urbana desde un valor estético con variables individuales y no desde la integralidad que conlleva la calidad ambiental del paisaje. Por su parte, en Santa Rosa Jáuregui es notorio que el paisaje urbano es poco atendido, excluyendo el centro de la localidad donde el sistema oficial concentra esfuerzos, pero hacia la periferia el detrimento ambiental se manifiesta en un paisaje deteriorado e inseguro. En lo que sí tienen similitudes ambos casos, es que las diferencias ambientales en el paisaje están ligadas con las necesidades y posibilidades individuales de los habitantes, esto es, un urbanismo construido por los propios ciudadanos, sea de buena o mala calidad, mientras que las autoridades son cómplices al permitir reconfiguraciones paisajísticas de evidente deterioro ambiental que no son atendidas de la misma forma que el centro de la ciudad.

Si bien el método permitió identificar esas diferencias ambientales, cabe señalar que también presentó algunas dificultades que deben ser consideradas en caso de ser replicado. En este contexto, la adaptación de la escala de análisis obligó a ampliar los rangos de registro de cada variable, situación que se manifestó en la necesidad de contar con tres veces más la cantidad de personas para el levantamiento de información, aumentaron los meses de registro y se produjo un ligero incremento económico del trabajo. Asimismo, los resultados otorgaron que la estética urbana del paisaje juega un papel fundamental en la calidad ambiental, por ello sería importante incluir un grupo temático que considere variables urbano-arquitectónicas (infraestructura, equipamiento, servicios y mobiliario urbano) en la valoración con el objetivo de contemplar la generalidad del entorno inmediato, ello permitiría no solo establecer sitios prioritarias, sino dirigir esfuerzos a corto, mediano y largo plazo y dosificar esfuerzos para que sea un apoyo más adecuado en el mejoramiento ambiental urbano.

Con los argumentos señalados, este trabajo presenta dos aportes, sea el método empleado y la identificación de sitios prioritarios. El primero refiere a la adaptación del método de Hernández (2015) a mesoescala, el cual permitió una mejor valoración de la calidad ambiental del paisaje urbano y colaboró con la identificación de sitios que comúnmente no suelen ser atendidos por el sistema oficial, pero denotan perjuicios ambientales. El segundo refiere a la ubicación exacta de más de cuarenta sitios de atención donde se concentran problemas en los tres grupos temáticos 
de análisis (agua, suelo y aire), lo cual contribuye con conocimiento e información de sitios poco o nada monitoreados. Además, esos aportes se presentaron a través de información clara y focalizada para que los habitantes y autoridades comprendan la condición de entornos inmediatos que cotidianamente observan, usan, manejan y administran, y que se encuentran en constante reconfiguración debido a la rápida urbanización, todo ello con el fin de mitigar perjuicios ambientales y que sirvan de apoyo en las estrategias de planeación y sustentabilidad urbana.

\section{Referencias bibliográficas}

ÁLVAREZ, M. La categoría de paisaje cultural. Revista de Antropología Iberoamericana, 2011, Vol. 6, No 1, p. 57-80.

ARRIAZA, M.; CAÑAS-ORTEGA, J.; CAÑAS-MADUEÑO, J. \& RUIZ-AVILES, P. Assessing the visual quality of rural landscapes. Landscape and Urban Planning, 2004, № 69, p. 115-125.

ARVIZU, C. Evolución urbana de Querétaro. Querétaro: Presidencia municipal de Querétaro y el Tecnológico de Monterrey, 2005.

BASSOLS, A. México: Formación de Regiones Económicas. México, D.F.: Universidad Nacional Autónoma de México, 1992.

BRAATZ, S. y KANDIAH, A. Utilización de aguas residuales urbanas para el riego de árboles y bosques. Unasylva, 2004, Vol. 47, N 185, p. 45-51.

BRICEÑO, M. y GIL, B. Calidad ambiental de la imagen urbana: Sectores La Parroquia, Alto Chama, Carrizal, Los Curos, Zona Industrial y barrios La Candelaria y San Buenaventura de la ciudad de Mérida-Venezuela. Fermentum. Revista Venezolana de Sociología y Antropología, 2003, Vol. 3, № 38, p. 445-485.

BRICEÑO, M.; OWEN, M. y CONTRERAS, W. Propuesta de un sistema de indicadores para evaluar la calidad visual del paisaje urbano. Ecodiseño y Sostenibilidad, 2011, Vol. 3, Nº 1, p. 65-104.

CABREIRO, C. y RODRÍGUEZ, I. Ciudad y territorio en clave de paisaje urbano contemporáneo en España y México. Cuadernos de Vivienda y Urbanismo, 2010, Vol. 3, Nº 6, p. 182-195.

DOMENE, E. y SAURÍ, D. Modelos urbanos y consumo de agua. El riego de jardines privados en la región metropolitana de Barcelona. Investigaciones Geográficas, 2003, №32, p. 5-17.

ELLARD, C. Ambientes de Bienestar. La ciudad y su importancia en tu vida. México, D.F.: Ediciones B, 2015.

FÉLIX, P. Impactos del crecimiento vertical en la expansión de la zona conurbada de Querétaro. Nuevo León. México: Tesis de Maestría, Facultad de Arquitectura, Universidad Autónoma de Nuevo León, 2015. 
GARCÍA, H. Valoración del paisaje para la planeación territorial de la microcuenca San José El Alto, Querétaro. Querétaro, México: Tesis de Maestría, Facultad de Ciencias Naturales, Universidad Autónoma de Querétaro, 2016.

GARCÍA-ESTRADA, M. y HERNÁNDEZ-GUERRERO, J. La capacidad de respuesta de los habitantes de Santa Rosa Jáuregui al riesgo asociado a inundaciones en la ciudad de Querétaro, México. CienciaUAQ, 2015, N², p. 1-17.

GODDARD, M.; DOUGILL, A. \& BENTON, T. Scaling up from gardens: biodiversity conservation in urban environments. Trends in Ecology \& Evolution, 2010, Vol. 25, № 2, p. 90-98.

GOMES, M. Desigualdade socioambiental no espaço urbano de Guarapuava. RA'EGA - O espaço Geográfico em Análise, 2010, № 20, p. 95-105.

GONZÁLEZ, C. Segregación urbana dirigida y segregación voluntaria: Querétaro, México. Ponencia presentada en el XXX simposio de la ICA. Viena, 2012. Disponible en Internet: http://fcps.uaq. $\mathrm{mx} /$ descargas/pnpc/3_personal_academico/nucleo_basico/carmen_imelda_gonzalez/produccion_academica/6.pdf

GUERRA, L. La valoración de la imagen urbana en la ciudad de Santa Clara. ISLAS, 2001, Vol. 43, $N^{\circ} 130$, p. 134-142.

HARVEY, D. Ciudades rebeldes. Del derecho de la ciudad a la revolución urbana. Madrid: Ediciones akal, 2013.

HARVEY, D. Justice, Nature and the Geography of Difference. New York: Wiley-Blackwell, 1997.

HERNÁNDEZ, J. Valoración visual de la calidad ambiental del área urbana de Querétaro, México: la compleja sencillez de valorar el entorno urbano. Revista de Geografía Norte Grande, 2015, No 61, p. $45-64$.

HERNÁNDEZ-GUERRERO, J.; LUNA-SORIA, H.; NAVARRETE-CARRILLO, A. y MARTÍNEZ-ROMERO, G. Expansión urbana y precariedad habitacional en el área urbana del municipio de Querétaro, México: 1980-2010. En: VIEYRA. A.; MÉNDEZ, Y. y HERNÁNDEZ-GUERRERO, J. (coordinadores). Procesos urbanos, pobreza y ambiente. Implicaciones en ciudades medias y megaciudades. Morelia: UNAM-CIGA, 2016, p. 109-124.

INSTITUTO NACIONAL DE ESTAdístICA Y GEOGRAFÍA (INEGI). Censo de Población y Vivienda 2010. Disponible en Internet: http://www.beta.inegi.org.mx/proyectos/ccpv/2010/

LALANA, J. El paisaje urbano histórico: Modas, paradigmas y olvidos. Ciudades, 2011, Vol. 14, № 1, p. 15-38.

LUCK, M. \& WU, J. A gradient analysis of urban landscape pattern: a case study from the Phoenix metropolitan region, Arizona, USA. Landscape Ecology, 2002, №17, p. 327-339. 
MADERUELO, J. El paisaje urbano. Estudios Geográficos, 2010, Vol. LXXI, № 269, p. 575-600.

MATSUOKA, R. \& KAPLAN, R. People needs in the urban landscape: Analysis of landscape and urban planning contributions. Landscape and Urban Planning, 2008, № 84, p. 7-19.

MUÑOZ-PEDREROS, A. La evaluación del paisaje: una herramienta de gestión ambiental. Revista Chilena de Historia Natural, 2004, №77, p. 139-156.

PACIONE, M. Urban environmental quality and human wellbeing-a social geographical perspective. Landscape and urban planning, 2003, Vol. 65, N 1, p. 19-30.

PELLOW, D. Social inequalities and environmental conflict. Horizontes antropológicos, 2007, Vol. $3, N^{\circ} 25$, p. $15-29$.

PÉREZ, E. Paisaje urbano en nuestras ciudades. Bitácora, 2000, Vol. 4, N 1, p. 33-37.

PROGRAMA DE LAS NACIONES UNIDAS PARA EL MEDIO AMBIENTE (PNUMA). Perspectivas del medio ambiente urbano. GEO Zona Metropolitana Querétaro. Querétaro: PNUMA, 2008.

PRUDHAM, S. Commodification. In: CASTREE, N.; DEMERITT, D.; LIVERMAN, D. \& RHOADS, B. (editors). A companion to Environmental Geography, London: Wiley-Blackwell, 2009, p. 123-142.

SÁNCHEZ, R. Horacio Capel. La morfología de las ciudades. Sociedad, cultura y paisaje urbano. Reseña de libro Vol-I, Revista de Geografía Norte Grande, 2004, № 32, p. 119-122.

SECRETARÍA DE DESARROLLO SOCIAL (SEDESOL) y CONSEJO NACIONAL DE POBLACIÓN (CONAPO). Catálogo. Sistema urbano nacional 2012. México. D.F.: Secretaría de Gobernación, 2012. Disponible en Internet:

http://conapo.gob.mx/work/models/CONAPO/Resource/1539/1/images/ParteslaV.pdf

STEWART, T.; MIDDLETON, P. \& ELY, D. Urban visual air quality judgments reliability and validity. Journal of Evironmental Psychology, 1983, №3, p. 129-145.

TEJEDA LE BLANC \& CÍA, S.C. Medición y adaptación de variables de actividad vehicular en ciudades tipo de México. México, D.F.: Comisión para la Cooperación Ambiental, 2009.

VEGA, S. Ciudades, localidades rurales y distritos electorales federales. En: CARRILLO, M.; ESTRADA, S. y TOSCANA, A. (editores). Imagen electoral de México (1980-2002), México D.F.: UAM-X/ CSH/Depto. De Política y Cultura, 2004, p. 43-47. 